\title{
Examination of neutrophil, platelet, and monocyte- lymphocyte ratios in adolescents with bipolar disorder-manic episode and depression
}

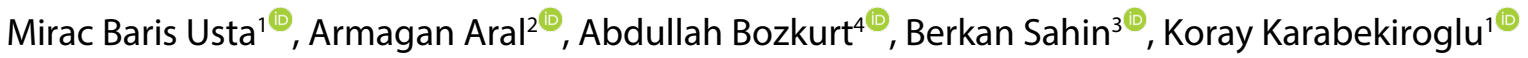 \\ 'Ondokuz Mayis University, Department of Child and Adolescent Psychiatry, Samsun - Turkey \\ ${ }^{2}$ Samsun Mental Hospital, Department of Child and Adolescent Psychiatry, Samsun - Turkey \\ ${ }^{3}$ Giresun University, Department of Child and Adolescent Psychiatry, Giresun - Turkey \\ ${ }^{4}$ Konya Training and Research Hospital, Department of Child and Adolescent Psychiatry, Konya - Turkey
}

\begin{abstract}
Objective: Neutrophil/lymphocyte ratio (NLR), platelet/lymphocyte ratio (PLR), and monocyte/lymphocyte ratio (MLR) are practical inflammation parameters. In bipolar disorder (BD) and major depressive disorder (MDD), these parameters were reported higher than in healthy controls (HC). We aim to compare NLR, PLR, MLR in HC and patients with MDD and BB-manic episode.

Method: Forty-six patients with MDD and 43 patients with BD hospitalized between 2013 and 2017 and $40 \mathrm{HC}$ were included in the study. White blood cell, neutrophil, lymphocyte, platelet, and monocyte numbers were entered retrospectively from complete blood counts made at the time of admission, and NLR, PLR, and MLR were calculated from these.

Results: NLR and PLR were revealed higher in MDD than HC. NLR and neutrophil values were higher in BD than HC, and there was a positive correlation between NLR and hospitalization period of patients with BD.

Conclusion: Findings of our study supported the inflammation hypothesis for MDD and BD in adolescents. Larger-scale studies are necessary to confirm these findings.
\end{abstract}

Keywords: Bipolar disorder, depression, inflammation, white blood cells

\section{INTRODUCTION}

Bipolar disorder (BD) and major depressive disorder (MDD) are psychiatric diseases that lead to high rates of functional impairment and can require hospitalization for treatment during mood episodes. In the literature, there are hypotheses suggesting that the etiology of $\mathrm{BD}$ and MDD is related to the immune system and inflammatory processes $(1,2)$. It has been reported that changes in the levels of acute-phase reactants and proinflammatory cytokines could play a role in the etiology of these disorders (3-5).

The neutrophil-lymphocyte ratio (NLR), the platelet-lymphocyte ratio (PLR), and the monocytelymphocyte ratio (MLR) are the most useful indicators of systemic inflammation $(6,7)$. In the literature, NLR was found to be higher in MDD and BD patients than in healthy controls (HC) (8-10). Patients in hypomanic/

How to cite this article: Usta MB, Aral A, Sahin B, Bozkurt B, Karabekiroglu K. Examination of neutrophil-, platelet-, and monocyte-lymphocyte ratios in adolescents with bipolar disorder-manic episode and depression. Dusunen Adam The Journal of Psychiatry and Neurological Sciences 2019;32:328-333.

Correspondence: Mirac Baris Usta, Ondokuz Mayis University, Department of Child and Adolescent Psychiatry, 55139 Atakum/Samsun - Turkey Phone: +90 3623121919 E-mail: dr.miracbarisusta@gmail.com 
manic and euthymic periods of BD have been seen to have a higher NLR than patients in depressive periods (8). However, according to a study published in 2017, there were contradictory findings or no difference found between euthymic and depressive periods in respect of NLR (11).

PLR is higher in $\mathrm{BD}$ patients compared to $\mathrm{HC}$ (12). Higher PLR levels have also been reported in patients with severe MDD compared to those with moderate and mild MDD (13). In a comparative study, MLR was found to be higher in $\mathrm{BD}$ patients than in the control group (14). A recent study of schizophrenia, $\mathrm{BD}$, and HC reported that higher NLR, PLR, and MLR values were observed in BD patients than in the control group (12). To the best of our knowledge, there has been no study comparing NLR, PLR, and MLR in adolescent patient groups with BD and MDD.

Chronic inflammatory diseases such as asthma and obesity often seen in children with a psychiatric diagnosis may indicate a relationship between psychiatric diagnoses and inflammation symptoms $(15,16)$. As cytokine production is different in children and adolescents than in adults, previous findings in the adult patient population may not be valid for children (17). Moreover, a sample consisting of children and adolescents may allow a reduction of the confounding role associated with the inflammatory process of comorbid diseases (18). Not only are there few studies related to psychiatric diseases and the inflammatory process in children and adolescents, but the small sample sizes in those studies have also restricted the examination of correlations between the stated variables with sufficient power (18).

This study aimed to examine the role of the inflammatory process in $\mathrm{BD}$ - manic episode and MDD. To this end, the parameters of NLR, PLR, MLR, and whole blood count were compared between BD and MDD patients and HC. The study hypothesized that the NLR, PLR, and MLR values would be higher in adolescents diagnosed and hospitalized with $\mathrm{BD}$ and MDD than in HC.

\section{METHOD}

\section{Participants and Procedure}

The study included 43 patients diagnosed with $\mathrm{BD}$ manic episode and 46 patients diagnosed with MDD who were hospitalized for the first time in the Pediatric Psychiatry Unit of Ondokuz Mayis University Medical Faculty between 2013 and 2017. The results of blood samples taken routinely during hospitalization were retrospectively evaluated following an automation process in the hospital. The blood samples had been taken within 24 hours of hospital admittance, and serum NLR, PLR, and MLR were examined. Patients who had a chronic illness (infectious diseases, hypertension, diabetes mellitus, autoimmune disease) other than schizophrenia or were taking drugs other than antipsychotic medicines (steroids, nonsteroidal anti-inflammatory drugs, antibiotics) that could interfere with complete blood count $(\mathrm{CBC})$ values were excluded from the study. Approval for the study was granted by the Ethics Committee of Ondokuz Mayis University no: B.30.2.ODM./20.08.1091-1146, dated 09.10.2017.

\section{Biochemical Analyses}

Samples were drawn into tubes with EDTA ethylenediaminetetraacetic acid for the $\mathrm{CBC}$, and the CBC was done on a CELL-DYN 3700 SL analyzer (Abbott Diagnostics, Chicago, USA). White blood cell (WBC), neutrophil, lymphocyte, platelet, and monocyte numbers were retrieved from complete blood counts at the time of admission, and NLR, PLR, and MLR were calculated from these values. Data for the healthy control group were obtained by a retrospective examination of the laboratory results of 40 adolescent bone marrow transplant donors in the same hospital. Volunteers donating blood to our hospital blood bank are examined for chronic diseases and any drugs they use. Blood donations are not accepted from patients with chronic disease or long-term drug use. The results of the blood samples taken from the control group were compared with those of the BD and MDD groups.

\section{Statistical Analysis}

Statistical analysis was performed using SPSS 22.0 (IBM, Chicago, IL, USA). Normal distribution of the data was assessed with the Kolmogorov-Smirnov test. For comparisons of two groups of normally distributed data, the Independent Samples t-test was applied, and for three groups, one-way ANOVA was used. For post hoc analysis, Bonferroni test was carried out. Spearman correlation analysis was used for correlation analysis. Multiple linear regression analysis with a backward elimination method was applied to the group using blood parameters and hospitalization period. A value of $\mathrm{p}<0.05$ was accepted as statistically significant.

\section{RESULTS}

In the demographic data, no significant difference was determined between the groups regarding age, gender, 
and length of hospital stay. The demographic findings are shown in Table 1.

As a result of the comparison of three groups, a statistically significant difference was determined in respect of NLR, neutrophil count, and lymphocyte count, while no significant difference was determined between the other parameters (Table 2). In the post hoc comparisons with Bonferroni test, statistically, significant differences were determined in respect of NLR ( $p=0.006)$ and neutrophil counts $(p=0.003)$ between the BD and HC.

The correlation of the hospitalization period and the blood parameter values in the MDD and BD groups was examined. A weak positive correlation was determined between NLR and hospitalization period in the BD group (Table 3).

Multiple linear regression analysis was applied with a backward elimination method between the length of stay (dependent variable) and NLR, PLR, and MLR (independent variables) values to the BD group. A model with NLR and PLR values was statistically significant $\left(\mathrm{R}^{2}=0.429, \mathrm{p}=0.005\right)$. The linear regression analysis is shown in Table 4.

\section{DISCUSSION}

In studies related to $\mathrm{BD}$ and inflammation, changes in cytokine profiles such as TNFa, IL-2 receptors, and IL-6, interferon- $\gamma$ have been previously reported (1921). IL-2, IL-6, and interferon- $\gamma$ have been found to decrease to normal values with three months of lithium treatment (22). Another marker that has been examined related to inflammation in BD is NLR. In a study published 2015 by Cakir et al. (23), it was shown that NLR and neutrophil count values were higher in BD patients and lymphocyte values lower compared to a healthy control group. In the current study, NLR and neutrophil count values were determined to be

Table 1: Comparison of demographic data of BD, MDD, and HC subjects

\begin{tabular}{lcccc} 
& MDD $(\mathbf{n}=\mathbf{4 6})$ & BD-Manic episode $(\mathbf{n = 4 3 )}$ & HC $(\mathbf{n = 4 0})$ & $\mathbf{p}$ \\
\hline Gender (female) & $17(36.9 \%)$ & $10(23.2 \%)$ & $15(37.5 \%)$ & $0.081^{1}$ \\
Age (years) & $15.21 \pm 1.41$ & $15.32 \pm 1.72$ & $14.82 \pm 1.79$ & $0.351^{2}$ \\
Length of hospital stay (days) & $10.43 \pm 10.53$ & $14.27 \pm 15.38$ & & $0.238^{3}$ \\
\hline
\end{tabular}

MDD: Major depressive disorder, BD: Bipolar disorder, HC: Healthy controls, ${ }^{1}$ Chi-square test, ${ }^{2}$ One-Way ANOVA test, ${ }^{3} \mathrm{~T}$-test.

Table 2: Comparisons of Neutrophil, Lymphocyte, Platelet, and Monocyte levels and NLR, PLR, and MLR ratios between the groups

\begin{tabular}{|c|c|c|c|c|c|}
\hline & $\begin{array}{c}\text { MDD } \\
(n=46) \\
\text { Mean士SD }\end{array}$ & $\begin{array}{c}\text { BD-Manic Episode } \\
\qquad(n=43) \\
\text { Mean } \pm \text { SD }\end{array}$ & $\begin{array}{c}\text { HC } \\
(n=40) \\
\text { Mean } \pm \text { SD }\end{array}$ & $\mathbf{F}$ & $\mathbf{p}$ \\
\hline NLR & $2.17 \pm 0.88$ & $2.43 \pm 1.21$ & $1.69 \pm 0.90$ & 5.705 & 0.004 \\
\hline PLR & $153.69 \pm 58.01$ & $140.01 \pm 61.01$ & $128.50 \pm 47.91$ & 2.954 & 0.118 \\
\hline MLR & $0.20 \pm 0.08$ & $0.31 \pm 0.13$ & $0.20 \pm 0.13$ & 1.829 & 0.108 \\
\hline Neutrophils (\%) & $4.02 \pm 1.33$ & $4.50 \pm 1.71$ & $3.54 \pm 1.04$ & 4.929 & 0.009 \\
\hline Lymphocytes (\%) & $1.98 \pm 0.56$ & $1.98 \pm 0.91$ & $2.34 \pm 0.60$ & 3.492 & 0.033 \\
\hline Platelets $10^{9} / \mathrm{L}$ & $281.34 \pm 59.72$ & $250.14 \pm 83.22$ & $277.77 \pm 47.46$ & 2.954 & 0.056 \\
\hline Monocytes & $0.38 \pm 0.12$ & $0.56 \pm 0.31$ & $0.42 \pm 0.13$ & 1.829 & 0.165 \\
\hline
\end{tabular}

MDD: Major depressive disorder, BD: Bipolar disorder, HC: Healthy controls, NLR: Neutrophil/lymphocyte ratio, PLR: Platelet/lymphocyte ratio, MLR: Monocyte/lymphocyte ratio.

Table 3: Correlation of the hospitalization period and the NLR, PLR and MLR values of the MDD and BD groups

\begin{tabular}{lcccc} 
& \multicolumn{2}{c}{ MDD hospitalization period (days) } & \multicolumn{2}{c}{ BD- manic episode hospitalization period (days) } \\
\cline { 2 - 5 } & $\mathbf{p}$ & $\mathbf{r}$ & $\mathbf{p}$ & $\mathbf{r}$ \\
\hline NLR & 0.610 & 0.077 & 0.040 & 0.315 \\
PLR & 0.909 & -0.017 & 0.695 & 0.062 \\
MLR & 0.926 & 0.014 & 0.939 & 0.012 \\
\hline
\end{tabular}




\begin{tabular}{|c|c|c|c|}
\hline Variable remaining in the model & Standardized $\beta$ & Adjusted $\mathbf{R}^{2}$ & $\mathbf{p}$ \\
\hline & & 0.429 & 0.005 \\
\hline NLR & 0.296 & & 0.009 \\
\hline PLR & 0.098 & & 0.031 \\
\hline
\end{tabular}

NLR: Neutrophil/lymphocyte ratio, PLR: Platelet/lymphocyte ratio, BD: Bipolar disorder.

statistically significantly higher in adolescents with $\mathrm{BD}$ and the lymphocyte values lower compared to HC. As all the BD patients evaluated in the current study were receiving treatment, the blood samples were taken in the manic phase. Yildiz et al. (8) found higher NLR values in $\mathrm{BD}$ patients in both the euthymic and manic episodes compared to HC. In a study by Kalelioglu et al. (24), although a significant difference was seen in varying NLR, neutrophil count and lymphocyte count values in the manic and euthymic periods of $\mathrm{BD}$ compared to the control group, no significant difference was observed between the values of the manic and euthymic periods.

The current study has shown a significant positive correlation between NLR and length of hospital stay in $\mathrm{BD}$ patients. It can be expected that those with a longer hospitalization have suffered a more severe manic episode. An increase in NLR as an inflammation marker according to the severity of the manic episode could affect this result. Given the retrospective design of the study and because objective measurements could not be used to evaluate the severity of the manic episode, the interpretation of this finding is limited. Future studies examining the relationship between NLR and BD would be helpful for a clarification of the correlation between NLR values and the severity of the manic episode.

In the current study, the NLR and PLR values in the MDD patients were found to be significantly higher and the lymphocyte count lower than in HC. In a prospective study by Demir et al. (9), higher NLR and neutrophil count and lower lymphocyte count were determined in patients with depression not receiving any pharmacological treatment compared to HC. Demircan et al. (25) reported that NLR was higher in depressed patients than in $\mathrm{HC}$, and a reduction in levels was determined in the third month of antidepressant treatment. It has previously been reported that acutephase reactants such as TNF- $\alpha$, IL- 1 , and IL- 6 are elevated in depressed patients and may be useful in the understanding of the etiopathogenesis (5). Increased depression rates in chronic inflammatory diseases and cytokines such as interferon- $\alpha$ that are used in immune treatment cause depression, supporting the view that there is a correlation between depression and the inflammatory process $(26,27)$. Some studies have emphasized that stressors in childhood have a role in triggering the process of the relationship between depression and inflammation, and it has been suggested that this patient group would be a good candidate for treatment with anti-inflammatory drugs (28-30). Although there are fewer studies of MDD and the inflammatory process in children and adolescents than in adults, in some studies, IL- 6 and interferon- $\gamma$ values were higher compared to the control group $(31,32)$. The retrospective design of the current study prevented an evaluation of the relationship of cytokines to the inflammatory process.

Like NLR, PLR is a useful marker for the systemic response to inflammation (6). In a study by Ozdin et al. (12), the PLR value of BD patients in the manic attack phase was found to be higher than that of HC. According to Kalelioglu et al. (24), while there was no significant difference between BD patients in the manic attack phase and a control group in respect of PLR, this ratio was found to be higher than in the controls when $\mathrm{BD}$ was in the euthymic phase. In the current study, as the BD patients were all in the manic attack phase, no significant difference was observed compared to the control group in respect of the PLR values. No previous study comparing the PLR values of MDD patients with $\mathrm{HC}$ could be found in the literature. In a study published in 2017 by Kayhan et al. (13), the PLR value of severe MDD patients was found to be higher than that of mild and moderate MDD patients. Furthermore, a recent study by Ozturk et al. (33) showed decreased MPV and NLR values after the treatment of depression. One of the findings of the current study was that the PLR values of the MDD patients were found to be higher than those of the control group. Although no objective measurement was made of the severity of depression in the current study, the correlation between length of hospital stay and the PLR value was evaluated and not found to be significant. Further studies evaluating the relationship of PLR with depression severity and duration would contribute to the literature related to this subject. 
There were some limitations to this study: we used a retrospective design, there was no evaluation of the severity and duration of manic and depressive phases and no assessment of the effect of the psychiatric drugs being used that could have been seen in the blood parameters. Generating the sample by selecting patients admitted to the psychiatry unit prevents generalization of the results. Further studies with more extensive samples from euthymic and depressive BD patients being treated both as in- and outpatients would contribute to the determination of inflammatory values as state and trait.

The results of this study demonstrated that NLR values in adolescents diagnosed with $\mathrm{BD}$ and $\mathrm{MDD}$ were higher and lymphocyte values lower compared to a control group. In addition to NLR, the neutrophil count, as an inflammation marker, was found to be higher in the BD patients compared to the control group and the PLR value was higher in MDD patients compared to the control group. In contrast to the study hypothesis, no difference was seen in the MLR values between the BD and MDD groups. The results of the study support the multi-systemic inflammatory process model related to BD and MDD in a patient group of children and adolescents that had been revealed in previous studies. There have not been sufficient studies with large samples of the pediatric and adolescent age group examining the relationship between psychiatric disease and the inflammatory process. Confounding findings of inflammatory diseases are not often seen in children and adolescents, and there is therefore a need for further studies to investigate the relationship between psychiatric diseases and inflammation in this age group. The current study can be considered as a contribution to the literature on this subject.

\begin{tabular}{|c|c|c|}
\hline \multicolumn{2}{|c|}{ Contribution Categories } & Author Initials \\
\hline \multirow{3}{*}{ Category 1} & Concept/Design & M.B.U., A.A., A.B. \\
\hline & Data acquisition & A.A., A.B., B.S. \\
\hline & Data analysis/Interpretation & M.B.U., K.K., B.S. \\
\hline \multirow{2}{*}{ Category 2} & Drafting manuscript & M.B.U., K.K., A.B. \\
\hline & Critical revision of manuscript & M.B.U., K.K. \\
\hline Category 3 & Final approval and accountability & M.B.U., K.K., A.A., B.S. \\
\hline \multirow{2}{*}{ Other } & Technical or material support & M.B.U. \\
\hline & Supervision & K.K. \\
\hline
\end{tabular}

Ethics Committee Approval: This study was approved by the local research ethics committee.

Informed Consent: Written informed consent was obtained from the patients and their legal guardians.

Peer-review: Externally peer-reviewed.
Conflict of Interest: Authors declared no conflict of interest.

Financial Disclosure: Authors declared no financial support.

\section{REFERENCES}

1. Leboyer M, Soreca I, Scott J, Frye M, Henry C, Tamouza R, Kupfer DJ. Can bipolar disorder be viewed as a multi-system inflammatory disease? J Affect Disord 2012; 141:1-10. [CrossRef]

2. Tuglu C, Kara SH. Depression, cytokines, and immune system. Bulletin of Clinical Psychopharmacology 2003; 13:142-150. (Turkish)

3. Munkholm K, Brauner JV, Kessing LV, Vinberg M. Cytokines in bipolar disorder vs. healthy control subjects: a systematic review and meta-analysis. J Psychiatr Res 2013; 47:1119-1133. [CrossRef]

4. Huang T-L, Lin F-C. High-sensitivity C-reactive protein levels in patients with major depressive disorder and bipolar mania. Prog Neuropsychopharmacol Biol Psychiatry 2007; 31:370-372.

5. Raison CL, Capuron L, Miller AH. Cytokines sing the blues: inflammation and the pathogenesis of depression. Trends Immunol 2006; 27:24-31. [CrossRef]

6. Zahorec R. Ratio of neutrophil to lymphocyte counts-rapid and simple parameter of systemic inflammation and stress in critically ill. Bratisl Lek Listy 2001; 102:5-14.

7. Balta S, Ozturk C. The platelet-lymphocyte ratio: a simple, inexpensive, and rapid prognostic marker for cardiovascular events. Platelets 2015; 26:680-681. [CrossRef]

8. Yildiz M, Batmaz S, Songur E, Sahin S, Demir O. Simple markers for subclinical inflammation in the different phases of bipolar affective disorder. Archives of Clinical Psychiatry - Revista de Psiquiatria Clinica 2016; 43:143-146. [CrossRef]

9. Demir S, Atli A, Bulut M, Ibiloglu AO, Gunes M, Kaya MC, Demirpence O, Sir A. Neutrophil-lymphocyte ratio in patients with major depressive disorder undergoing no pharmacological therapy. Neuropsychiatr Dis Treat 2015; 11:2253-2258. [CrossRef]

10. Semiz M, Yildirim O, Canan F, Demir S, Hasbek E, Tuman TC, Kayka N, Tosun M. Elevated neutrophil/lymphocyte ratio in patients with schizophrenia. Psychiatr Danub 2014; 26:220225.

11. Ayhan MG, Cicek IE, Inanli I, Caliskan AM, Ercan SK, Eren I. Neutrophil/lymphocyte and platelet/lymphocyte ratios in all mood states of bipolar disorder. Psychiatry and Clinical Psychopharmacology 2017; 27:278-282. [CrossRef]

12. Ozdin S, Sarisoy G, Boke O. A comparison of the neutrophillymphocyte, platelet-lymphocyte and monocyte-lymphocyte ratios in schizophrenia and bipolar disorder patients: a retrospective file review. Nord J Psychiatry 2017; 71:509-512.

13. Kayhan F, Gunduz S, Ersoy SA, Kandeger A, Annagur BB. Relationships of neutrophil-lymphocyte and platelet-lymphocyte ratios with the severity of major depression. Psychiatry Res 2017; 247:332-335. [CrossRef]

14. Drexhage RC, Hoogenboezem TH, Versnel MA, Berghout A, Nolen WA, Drexhage HA. The activation of monocyte and T cell networks in patients with bipolar disorder. Brain Behav Immun 2011; 25:1206-1213. [CrossRef] 
15. Ortega AN, Huertas SE, Canino G, Ramirez R, Rubio-Stipec M. Childhood asthma, chronic illness, and psychiatric disorders. J Nerv Ment Dis 2002; 190:275-281. [CrossRef]

16. Goldstein BI, Liu SM, Zivkovic N, Schaffer A, Chien LC, Blanco C. The burden of obesity among adults with bipolar disorder in the United States. Bipolar Disord 2011; 13:387-395. [CrossRef]

17. Lilic D, Cant AJ, Abinun M, Calvert JE, Spickett GP. Cytokine production differs in children and adults. Pediatr Res 1997; 42:237-240. [CrossRef]

18. Mitchell RH, Goldstein BI. Inflammation in children and adolescents with neuropsychiatric disorders: a systematic review. J Am Acad Child Adolesc Psychiatry 2014; 53:274-296. [CrossRef]

19. Barbosa IG, Huguet RB, Mendonca VA, Sousa LP, Neves FS, Bauer ME, Teixeira AL. Increased plasma levels of soluble TNF receptor I in patients with bipolar disorder. Eur Arch Psychiatry Clin Neurosci 2011; 261:139-143. [CrossRef]

20. Breunis MN, Kupka RW, Nolen WA, Suppes T, Denicoff KD, Leverich GS, Post RM, Drexhage HA. High numbers of circulating activated $\mathrm{T}$ cells and raised levels of serum IL-2 receptor in bipolar disorder. Biol Psychiatry 2003; 53:157-165.

21. Su KP, Leu SJ, Yang YY, Shen WW, Chou YM, Tsai SYM. Reduced production of interferon-gamma but not interleukin-10 in bipolar mania and subsequent remission. J Affect Disord 2002; 71:205-209. [CrossRef]

22. Boufidou F, Nikolaou C, Alevizos B, Liappas IA, Christodoulou GN. Cytokine production in bipolar affective disorder patients under lithium treatment. J Affect Disord 2004; 82:309-313.

23. Cakir U, Tuman TC, Yildirim O. Increased neutrophil/ lymphocyte ratio in patients with bipolar disorder: a preliminary study. Psychiatr Danub 2015; 27:180-184.

24. Kalelioglu T, Akkus M, Karamustafalioglu N, Genc A, Genc ES, Cansiz A, Emul M. Neutrophil-lymphocyte and plateletlymphocyte ratios as inflammation markers for bipolar disorder. Psychiatry Res 2015; 228:925-927. [CrossRef]

25. Demircan F, Gozel N, Kilinc F, Ulu R, Atmaca M. The impact of red blood cell distribution width and neutrophil/lymphocyte ratio on the diagnosis of major depressive disorder. Neurol Ther 2016; 5:27-33. [CrossRef]

26. Kenis G, Prickaerts J, van Os J, Koek GH, Robaeys G, Steinbusch HW, Wichers M. Depressive symptoms following interferon- $\alpha$ therapy: mediated by immune-induced reductions in brainderived neurotrophic factor? Int J Neuropsychopharmacol 2011; 14:247-253. [CrossRef]

27. Gibney SM, Drexhage HA. Evidence for a dysregulated immune system in the etiology of psychiatric disorders. J Neuroimmune Pharmacol 2013; 8:900-920. [CrossRef]

28. Danese A, Moffitt TE, Pariante CM, Ambler A, Poulton R, Caspi A. Elevated inflammation levels in depressed adults with a history of childhood maltreatment. Arch Gen Psychiatry 2008; 65:409-415. [CrossRef]

29. Miller GE, Cole SW. Clustering of depression and inflammation in adolescents previously exposed to childhood adversity. Biol Psychiatry 2012; 72:34-40. [CrossRef]

30. Tyring S, Gottlieb A, Papp K, Gordon K, Leonardi C, Wang A, Lalla D, Woolley M, Jahreis A, Zitnik R, Cella D, Krishnan R. Etanercept and clinical outcomes, fatigue, and depression in psoriasis: double-blind placebo-controlled randomized phase III trial. Lancet 2006; 367:29-35. [CrossRef]

31. Gabbay V, Klein RG, Guttman LE, Babb JS, Alonso CM, Nishawala M, Katz Y, Gaite MR, Gonzalez CJ. A preliminary study of cytokines in suicidal and nonsuicidal adolescents with major depression. J Child Adolesc Psychopharmacol 2009; 19:423-430. [CrossRef]

32. Gabbay V, Klein RG, Alonso CM, Babb JS, Nishawala M, De Jesus G, Hirsch GS, Hottinger-Blanc PM, Gonzalez CJ. Immune system dysregulation in adolescent major depressive disorder. J Affect Disord 2009; 115:177-182. [CrossRef]

33. Ozturk A, Sahan E, Mircik AB, Deveci E, Yilmaz O, Kirpinar I. Mean platelet volume and neutrophil to lymphocyte ratio decrease in patients with depression with antidepressant treatment. Archives of Clinical Psychiatry - Revista de Psiquiatria Clinica 2019; 46:9-13. [CrossRef] 